\title{
Familial spontaneous pneumothorax
}

INSERM

\section{Source}

INSERM. (1999). Orphanet: an online rare disease and orphan drug data base. Familial spontaneous pneumothorax. ORPHA:2903

Familial spontaneous pneumothorax is a rare, genetic pulmonary disease characterized by the uni- or bilateral accumulation of air in the pleural cavity in persons with a positive family history and no underlying lung disease or previous chest trauma. Patients typically present dyspnea associated with acute onset of sharp and steady pleutiric chest pain of variable severity (which resolves within $24 \mathrm{~h}$ even though pneumothorax is still present). Reflex tachycardia and/or respiratory or circulatory compromise may be observed. Other syndromes (e.g. Birt-Hogg-Dube, Marfan or Ehlers-Danlos syndromes) may be associated. 